and to find some way of showing how upon the profound fainting attack convulsions would ensue, and how upon convulsions stupor would follow. If this were positively desirable it would not be difficult to bring in Kussmaul's convulsions from anzemia to explain the onset of the spasmodic movements; for if indeed it be a law of the vertebrate organism that a discharge in convulsion occurs when bloodlessness is on the point of becoming fatal to the life of the brain, then a prolonged stoppage of the heart would fall under such law, and convulsions be the result. Nay, we may further here observe that in a certain degree there is in such a law that kind of adaptation to purpose which it is so great a satisfaction to perceive, seeing that when the heart's beat stops the arteries empty themselves, and then tension is done away, and it requires at least six or seven heartfuls of blood to restore arterial tension; moantime, with the removal of arterial tension, the ris a tergo on the whole circulation is lost, and the blood is no longer pushed round in a continuous course, so that it would therefore tend to stop in the veins, and in the abdominal veins alone there is room for the whole of the blood; therefore, with all the blood in the veins, and with no ris a tcrgo to act on them, where should the heart get its six or seveu charges of blood to start arterial tension once more? But the veins of the limbs have valves that prevent reflux of the blood, and convulsions compress the veins, and drive to the heart the necessary amount to keep the arteries full.

And, indeed, $i$ is quite probable that this is the purpose or use of the convulsions. Neither does it gainsay such a use that the convulsions become extreme and pass beyond the service for which they are adopted. For take the parallel sase of the plainly conservative spasm of a cough whose object is beyond doubt to expel undesirable contents from the windpipe; do we not find cough sometimes so vigorously acting in excess of its daties that we are at our wits' end to find some means of keeping this otherwise beneficent contrivance within due bounds? Likewise also, if we ask why stupor should succeed to convulsions, we may think this, too, a natural consequence of the convulsions, and we may also perceive that it tavours recovery. For convulsion is no mere exertion, as in healthy exercise; but it is the exertion of otherwise dying nervous centres called out not by the wholesome infiaence of sufficient or redundant supply, but brought to pass by desperate starvation, and therefore in the matter of exhaustion not to be put on a par with normal fatigue. Then what more likely than extreme exhaustion, and what better than a short deep sleep in which the senses are, if I may so speak, closed for repairs? An insensibility which is thus negative and whose service is plainly to allow time for the centres to recover themselves, is not of itself to be dreaded nor thought of as a terrible thing. It need not be set down to any overpowering positive cause on the baseless old-fashioned theory of congestion of the braiu. But here too, in a more dangerous way, we may find ourselves troubled with an excess of what is designed for rood, and just as cough may need checking, and as convulsions may prove extreme, so stupor may be protracted, and the sleep which was intended to refresh may not restore excitability, but become longer and deeper, until the person dies in a state of coma. And the normal stupor of the epileptic attick becomes thus extreme and fatal under conditinns that sufficiently explain the occurrence. For such fatal coma never happens in the epilepsy of young or vigorous 3ubjects when the brain is well nourished and capable of quick recuvery. It is in old age that it occurs, or at the close of a long course of cerebral exhaustion, especially when an impure state of the blood adds another cause of stupor, as in cases of protracted jaundice, or diabetes, or throaic runl disease, which not unfrequently terminute by a surden epileptiform coma or in old alcoholism in unstable brains. In these cases essentially rileptic attacks ocenr in which there is little or no convulion and the person appears seized with sudden coma. But a rons of the epilepric nature of such attacks it is remark. is tht : n the description of them under the erroneous title of "arniluctiorm cerebral congestion" it is stated that the ralis di-puars at the wrist in the onset. Now, after the ches whin I have given I consider this to be evidence of the ejileitic nature of these attacks. For clinical evidence of tha connexion of such attacks in individual cases with the history of epilepsy I have already referred to Trousseau's lecture on the subject. But if I had time I could give many cases of the kind from my own experience.

\section{CHRYSOPHANIC ACID AND PSORIASIS.}

\section{By M. CHARTERIS, M.D.,}

PROFESSOR OF THERAPEUTICS AND MATERIA MEDICA, GLASGOW UNI VERSITY, AND PHYSICIAN TO THE GLASGOW ROYAL INFIRMARY.

THE circumstances under which I was induced to try chrysophanic acid, as indicated by the correspondence in your journal, briefly stated, are as follows:-

A boy of nine years of age was admitted into my wards on April 5th last, covered, as the ward journal states, "with a scaly eruption, which came on about three years ago, and gradually extended until it embraced the whole body, being, however, most marked and patchy at the outside of the knees and elbows." He was ordered to be rubbed with the chrysophanic acid ointment (one drachm to one ounce of vaseline), and four days afterwards the nurse informed me that he had been sick and had vomited. On inquiring a little further into the matter, I made the remark to my clinical class, "I wonder if the application of the acid could have done this," and I stated " that I would on a subsequent occasion test the ointment with a view to elucidating the truth." Meanwhile I discontinued to employ the acil to the boy in the same strength, making the proportion half a drachm to the ounce; and he was dismissed well on May 3rd, without any further untoward symptoms. In accordance with the view suggested, the next patient admitted into the male wards was only rubbed with the acid of the same strength on one side of the body-the other being untouched. Both sides healed, but some dubiety existed on my mind, and also on that of my assistant, as to the truthfulness of the patient's statement, for we suspected, in his anxiety to become well, he had surreptitiously applied it to both sides. In the case also during the same summer of a female patient, we were suspicious that the nurse, somewliat inexperienced and zealous, had occasionally and intentionally forgotten the directions given and used it on places we had warued her to avoid. In publishing my clinical retrospect in THE LANCET of last autumn, I alluded to this, and said with regard to the chrysophanic acid ointment: "A singular circumstance was noted-viz, that the acid rubbed in must have some constitutional action, for if applied ouly to one side of the body it seems eventually, though more slowly, to remove the scales from the other. This observation, though true in one case, was not so marked in another, and woukd require further verification."

Continuing my narrative, I may state that the next case of psoriasis was admitted on Nov. 18th, 1880. This man, aged twenty-two, had twice before been under treatment in the infirmary for the same complaint, and on both occasions had been treated by arsenic with the result that in six weeks he had left the wards well. The last admission was in 1875 , and he stated that since then the eruption had appeared every autumn, but not to any great extent. Six months ago it was very apparent on the elbows and knees, and since then it had spread to the arms and legs, aud, as noted now, it is said to extend from the arms and leins over the whole body.

On the 21 st Nov. (three days after admission) :-One arm and leg were ordered to be covered with close-fitting flannel, and the ointment of the strength previously mentioued to be rubbed in over the exposed parts. On the lst Dec. the ointment was rubbed in for the last time, and twenty-four hours afterwards a bath was given. On the 6th December it is noted " that the skin on both sides is now clean and smooth, and the patient was dismissed 'cured.'

In the next case, that of a female aged seventeen, the history and appearance were as follows:-_" She had been under treatment three years previonsly, and had been treated successfully by me with chrysophanic acid. Six months ago the disease appeared again, and at present psoriasis spots are observed on the chest and back, circumscribed and not very numerous. But over the extensor surface of the arm there are large silvery patches, and on the outside of the knees and front of the legs and thiohs the erustion is very marked." Stringent precautions were taken in this case to guard againt any error in the one-sided application of the ointment, flannel padded with cotton-wool was applied from the upper part of the thigh to the ankle, and secured by tapes so that the ointment could in no way affect it. Two days after admission treatment was commenced by rubbing in the ointment to all the other parts implicated. This "rubbing in" was continued daily for ten days. The 
nurse used her hand, not a cloth. Fully two ounces were so used every day for four days, until the scales were thoroughly removed, after that about one ounce only of the ointment was applied. Ten days after the commencement of treatment it was found, on taking off the bandages, that the scales had commenced to disappear, the disappearance being most evident at the circumference. On the centres of the patches a few scales were still observed. The skin was left on the previously scaly surface white and clean. A week later the parts rubbed were completely free from scales, and the parts covered very nearly so, with the exception of one or two spots about the size of a pin head, which were situated on the centre of the previously scaly patch. The patient was ordered a bath, and a small bread and water poultice was applied over the previously covered leg. Three poultices in all were so applied on three successive days, and it was found after that time the skin was left clean and whole, and not discoloured as the other side was by the application of the ointment. In this condition the patient was shown to my class at the university, and I have no doubt they will testify to the appearance mentioned. I may add that the patient remained in the ward after this for a month, but the eruption did not reappear. The total quantity of ointment used in this case on twenty-four applications was thirty-two ounces, of the strength of one drachm to the ounce of lard.

It will be observed from the history of these cases-1. That the ointment was applied with no stinted hand, but, as the nurse states, rubbed in until it had been all absorbed. 2. That the strength of the ointment was perhaps stronger than that generally used--viz, one drachm to the ounce. 3. I venture on no speculation as to how chrysophanic acid may act if given internally. I simply state careful, well-recorded facts with regard to the influence of its one-sided application, and these facts can be corroborated without reservation by many who watched with interest the progress of the experiments.

Glasgow.

\section{ON WOUNDS OF THE KNEE-JOINT.'}

\section{BY WALTER RIVINGTON, F.R.C.S. ENG.,} SURGEON TO THE LONDON HOSPITAL.

THE object of this communication is essentially practical. Discarding all theory, setting aside all questions concerning germs and bacteria, I am desirous of contrasting the results of wounds of the knee-joint treated according to the rules of Listerism with those obtained under other methods of dressing, and of eliciting experience on both sides of the question. The records of cases occurring before the introduction of strict antiseptic precautions will be especially valuable. As I purpose confining my remarks mainly within the range of my own observation, it will, I think, be most convenient to relate at the outset the most recent example of wound of the knee-joint which has occurred in my practice, and to make it the text of my paper.

The subject of the injury was one Edward G-, fortysix years of age, a cab-proprietor. On the 19th of May, being the worse for liquor, he fell or was thrown from the box of his cab. From alcoholic causes he was unable to give any positive account of what happened, but he was inclined to think that the wheel of the cab passed over him. He was admitted during the evening of the 19 th, with a jagged wound over the right patella about the size of a shilling, and looking to the superficial eye as if it were merely a graze of the skin. My house-surgeon, Mr. Lawt.on, however, found an aperture at the upper part of the wound from which some serous fluid issued. This aperture admitted a probe, and, with some difficulty, the track of a sinus was found leading upwards and outwards for a couple of inches. There was no other injury anywhere. The patient was sent to bed, and an ice-bag was applied to the knee. The following afternoon he was seen by myself. The knee-joint was swollen, looked inflamed, and was considerably hotter to the touch than the corresponding joint on the left side. The natural outlines of the joint were obscured, finid inside the joint distending it so as to obliterate the hollows which are observable in the normal condition by the side of the patella and its ligament. Some pus could be

1 A paper read before the West Kent Medico-Chirurgical and pressed out of the small aperture at the upper part of the wound. Having heard Mr. Lawton's account of his exploration with the probe, and of the free escape of serous fluid the day before, and having regard to the distended condition of the joint, I thought that it would be advisable to slit up the sinus, and ascertain the condition of the parts beneath the skin. Thinking it probable that there might be a wound of the joint, I procured a steam-spray producer and allowed it to play upon the wound for a few minutes. A director was then introduced into the sinus, and the sinus was laid open. This done, there appeared a jagged hole in the quadriceps extensor tendon above the patella, and through this lace. rated foramen I introduced my carbolised finger behind the patella into the knee-joint, and explored the interior. Then I pressed out of the joint a considerable quantity of turbid serous fluid, almost purulent, and injected into it three or four large syringefuls ot a solution of carbolic acid ( 1 in 19). Finally the joint was emptied as far as possible of all fluid, a drainage-tube passed into it behind the patella, and the wound dressed in the usual manner with protective and gauze. A back splint was fixed to the limb. On the 2lst the patient complained of a good deal of pain in the knee, and experienced a sinking feeling due to the deprivation of his customary stimulants. The record for the 22nd says-_" The patient is much better this morning has slept well; the knee is much easier." Temporature morning $101^{\circ} 6^{\circ}$; evening $1014^{\circ}$. On Sunday evening, the $23 \mathrm{rd}, \mathrm{I}$ redressed the wound and withdrew the drainagetube. There was very little discharge. The temperature continued high for a day or two, being $103^{\circ}$ on the evening of the 24 th and $102^{\circ}$ on the 25 th, but the patient remained remarkably we'l and amused himself with reading during the day. Occasionally he had some painfal twinges, but there was no constitutional disturbance or swelling of the limb, and he took all his fluid diet with relish. The wound pursued a perfectly normal course, gradually cleaning and granulating healthily, and as soon as some of the tendinous fibres which had been damaged had come away the aperture lead ing into the joint entirely closed. It is noted that the tem. perature on the 19 th was up to $103^{\circ}$, and on the 21 st and 24 th to $101^{\circ}$, but there was nothing to account for this record, and the only way in which I can explain it is by supposing that it was due to the absorption of the effusion in and around the joint. The patient remained some weeks in the hospital, as cicatrisation of the superficial wound was slow He left in July to return to his occupation, sooner than I wished him to do, and before the joint had regained its freedom of movement. When I saw him in August he was walking about, and stated that the stiffness was passing away. A fortnight ago he came to see me at the hospital in excellent health, with a freely movable joint, and in a most grateful frame of mind.

Now whether we are or are not disposed to assign the favour. able issue in this case to the Listerian method, it will be admitted that the result is highly satisfactory, and inrites us to apply the method without reserve to any wounds of joints which may present themselves in the clinic. Although well aware that "one swallow does not make a summer," am strongly inclined myself to attribute the freedom from constitutional disturbance and the preservation of a serrice. able joint, withont the previous exhibition of violent local inflammation and its effects, to the adoption of the carbolic acid treatment, and I am influenced by several considera. tions, which I will state as briefly as possible. They are considerations arising out of the case itself, out of the experience of surgeons prior to the adoption of the Listerian system, and out of the experience of surgeons who have carried out that system in its integrity. If we regard the case itself we find that the joint had already begun to inflame, and that suppuration was imminent at the time the treatment was commenced. The surface over the joint was hot and tender, and the joint itself contained a considerable quantity of turbid serum. Supposing, under these circunstances, with a burrowing passage leading to bruised tissues destined to slough, and communicating on the one side with the air, and on the other with the cavity of the joint distended with a fluid capable of putrefaction, I had left the case to the vis medicatrix naturo, aided only by rest on splint, evaporating lotions, and ice-bags, is it reasonable to believe that as good a progress and result would have leen recorded? Or supposing that, without going to the extrems of the spray and gauze, I had thought it advisable to assi: the vis medicatrix naturce a little further, and had slit up the sinus, had passed my cleansed finger into the joint 